\title{
Trabalho escravo contemporâneo: o caso trabalhadores da Fazenda Brasil Verde
}

vs. Brasil

Contemporary Slave Labor: the Case Trabalhadores da Fazenda Brasil Verde vs. Brazil

Juliana Markendorf Noda ${ }^{1}$

Thâmisa Gonzalez de Oliveira²

\section{RESUMO}

Este presente trabalho tem por finalidade ampliar a discussão sobre o caso Fazenda Brasil Verde vs. Brasil, o primeiro caso sobre escravidão levado a julgamento na Corte Interamericana de Direitos Humanos, a partir da perspectiva do trabalho escravo contemporâneo, cujo combate deve ser intensificado através da atuação estatal.

Palavras-chave: escravidão; Fazenda Verde vs. Brasil.

\section{ABSTRACT}

This present study aims to broaden the discussion on the Case Fazenda Brasil Verde vs. Brazil, the first case of slavery led to the judgment in the Inter-American Court of Human Rights, from the perspective of the contemporary slave labor, whose combat should be intensified through state action.

Key-words: slavery; Fazenda Verde vs. Brazil.

\section{DIREITO DO TRABALHO}

Desde o século XVIII, o conceito de direito e garantias fundamentais é discutido. Porém, foi apenas após o advento da Segunda Guerra Mundial, com embasamento nas constituições de alguns países, como França e Alemanha, que os direitos fundamentais relativos ao trabalho foram incorporados à Constituição brasileira.

Na Constituição de 1988, os princípios da dignidade da pessoa humana, da valorização do trabalho, da justiça social e da submissão da propriedade à sua função

${ }^{1}$ Graduanda em Direito, Unicuritiba, Curitiba, Brasil.

${ }^{2}$ Advogada, Curitiba, Brasil. 
socioambiental foram evidenciados e, com essa inovação, foi demarcada a evolução da legislação trabalhista que ocorreu no país.

A partir da promulgação do atual instrumento normativo, o trabalho, então, passou a ser valorizado e considerado um dos princípios centrais da democracia brasileira, consistindo em uma das formas mais expressivas de afirmação do ser humano ${ }^{3}$. Dessa maneira, a Carta Magna nacional optou por enfatizar e proteger o trabalho regulado, posto que é o modo pelo qual a maior parte das pessoas se insere na sociedade, demonstrando, dessa maneira, como a democracia pode ser exercida na vida social.

Nesse sentido e segundo o ensinamento de Norberto Bobbio, a democracia é “[...] um princípio igualitário na medida em que pretende fazer com que prevaleça a força do número sobre a força da individualidade singular" ${ }^{4}$, em outras palavras, aufere poder de decisão aos indivíduos.

Assim, não há como negar que, ao proteger o trabalho e conceder direitos e garantias fundamentais relacionados a ele, a Constituição estaria assegurando que os cidadãos da República Federativa do Brasil passariam a participar da camada monetariamente ativa, de modo que seriam conferidos mais poderes a esses indivíduos e a mão de obra das pessoas que vivem neste país seria amplamente valorizada.

Ademais, não restam dúvidas quanto à intenção de proteção do trabalho regulado, ou seja, do pleno emprego, conforme se encontra normatizado no artigo 170 , inciso VIII, da Constituição federal. Tentou-se, dessa forma, proteger a mão de obra que, sujeita a proteções e garantias determinadas por lei, englobaria a tutela dos trabalhadores.

Essa situação se deve ao fato de que, normalmente, os empregados que não são regulados tendem a ter seus ganhos reduzidos e seus direitos desrespeitados. Assim, a regulamentação do trabalho procura evitar tais problemas e inserir o prestador de serviços na sociedade economicamente ativa, bem como lhe proporcionar um modo digno de viver, seja econômico, social, familiar, e, principalmente, evitar que trabalhadores sejam sujeitados a trabalhar em condições análogas à de escravo.

\footnotetext{
3 DELGADO, Maurício Goldinho. Direitos fundamentais na relação de trabalho. Revista de direitos e garantias fundamentais. n. 2. 2007. p. 15.

${ }_{4}$ BOBBIO, Norberto. Liberalismo e democracia. Tradução de Marco Aurélio Nogueira. São Paulo: Brasiliense, 2000. p. 58.
} 


\section{TRABALHO ESCRAVO CONTEMPORÂNEO}

Em maio de 1888, a assinatura da Lei Áurea pela princesa Isabel iniciou um novo marco na história e aboliu a escravidão no Brasil. Todavia, mais de um século depois, ainda é necessário manejar e combater essa forma absurda de exploração da mão de obra no país.

Entretanto, mesmo com a publicação da Lei 3.353/1888, não é incomum empregadores desrespeitarem os princípios, direitos e garantias fundamentais assegurados pela Constituição federal quando ocorre a imposição, aos seus empregados, do trabalho forçado e/ou em condições degradantes, como demonstra o Índice de Escravidão Global de 2014, realizado pela Fundação WalkFree5.

O trabalhador pode ser submetido a um trabalho escravo ou a um trabalho com condições análogas à de escravo. No primeiro caso, o trabalho pode se dar de duas maneiras: ou é caracterizado por ser forçado ou é realizado de forma voluntária, mas, após determinado período de tempo, toma-se conhecimento de que se tratava de trabalho escravo, quando há a necessidade, por exemplo. Por outro lado, a segunda forma de trabalho acontece quando o trabalhador tem a sua liberdade limitada e/ou quando é submetido a situação que não está de acordo com a dignidade da pessoa humana.

Como esses tipos de trabalho afetam não só a liberdade, mas também a própria dignidade da pessoa humana e todos os valores de uma sociedade embasada nesse princípio, eles atentam diretamente contra os preceitos elencados na Carta Magna nacional, que em seu preâmbulo defende a liberdade e o bem-estar; em seu artigo 1ํㅡ, inciso IV, os valores sociais do trabalho; em seu artigo $5^{\circ}$, garante aos brasileiros e aos estrangeiros residentes no país a inviolabilidade da sua liberdade e, também, determina, no inciso XLI do mesmo artigo, que a lei punirá qualquer discriminação atentatória dos direitos e liberdades fundamentais.

Porém, não é só esse instrumento normativo superior que defende a liberdade. O Código Penal brasileiro é categórico ao determiná-la como bem jurídico protegido e, como forma de resguardar esse direito, pune quem o desrespeita:

\footnotetext{
${ }^{5}$ CAMPOS, Ana Cristina. No Brasil, situação análoga à escravidão atinge 155,3 mil pessoas, diz o relatório Índice de Escravidão Global 2014. Disponível em: <http://www.ecodebate.com.br/2014/11/18/nobrasil-situacao-analoga-a-escravidao-atinge-1553-mil-pessoas-diz-o-relatorio-indice-de-escravidaoglobal-2014/>. Acesso em: 4 de abril de 2016.
} 
Artigo 149. Reduzir alguém a condição análoga à de escravo, quer submetendoo a trabalhos forçados ou a jornada exaustiva, quer sujeitando-o a condições degradantes de trabalho, quer restringindo, por qualquer meio, sua locomoção em razão de dívida contraída com o empregador ou preposto.

Pena - reclusão, de 2 (dois) a 8 (oito) anos, e multa, além da pena correspondente à violência.

$\S 1$ o Nas mesmas penas incorre quem:

I - cerceia o uso de qualquer meio de transporte por parte do trabalhador, com o fim de retê-lo no local de trabalho;

II - mantém vigilância ostensiva no local de trabalho ou se apodera de documentos ou objetos pessoais do trabalhador, com o fim de retê-lo no local de trabalho.

$\S 2^{\circ}$ A pena é aumentada de metade, se o crime é cometido:

I - contra criança ou adolescente;

II - por meio de preconceito de raça, cor, etnia, religião ou origem.

Dessa forma, resta claro que trabalho escravo ou análogo ao de escravo é muito mais do que a baixa ou a falta de remuneração. Vai além das violações ao submeter os trabalhadores a condições que confrontam a dignidade da pessoa humana, de modo que significa a supressão da liberdade, incorrendo em grave violação de direitos humanos.

Assim, cabe ressaltar que o Brasil foi o primeiro país a admitir, perante a Organização Internacional do Trabalho (OIT), que existiam casos de trabalho escravo em território nacional. Infelizmente, essa é uma realidade muito presente no país, de modo que o governo tenta combater o expressivo número de pessoas submetidas a essa espécie de trabalho com a criação de leis, a intervenção do Ministério Público do Trabalho e a adesão aos tratados internacionais.

\section{O SISTEMA INTERAMERICANO DE DIREITOS HUMANOS}

O Sistema Interamericano de Proteção dos Direitos Humanos foi criado e consolidado através da Organização dos Estados Americanos (OEA), organização instituída com o objetivo de promover ordem de paz e justiça no âmbito dos Estados do continente americano.

O sistema é composto por dois órgãos: a Comissão Interamericana de Direitos Humanos, que atua na promoção da observância e defesa dos direitos humanos e também oferece ações de responsabilidade internacional contra os Estados, e a Corte Interamericana de Direitos Humanos, que atua no julgamento das referidas ações. 
Dessa maneira, ambos os órgãos do sistema possuem competência para realizar intervenção e atuar quando um Estado-parte for acusado de violação de tratado ou convenção.

O Estado tem o dever de respeitar os direitos e as liberdades e de garantir o livre e pleno exercício de jurisdição, de acordo com o art. 1ํ da Convenção Americana sobre Direitos Humanos. Deve também adequar sua normatização interna, de acordo com o art. $2^{\circ}$ do mesmo dispositivo e o art. 27 da Convenção de Viena sobre o Direito dos Tratados.

Seguindo essa linha, a responsabilidade internacional do Estado encontra respaldo no art. 63 da Convenção Americana sobre Direitos Humanos, cujo reflexo provém de norma consuetudinária e constitui um dos princípios fundamentais de direito internacional sobre a responsabilidade dos Estados. Segundo André de Carvalho Ramos, a responsabilidade internacional do Estado consubstancia-se na obrigação de reparar danos da violação de norma do direito internacional. ${ }^{6}$

Desse modo, é imputável ao Estado quando, por ação ou omissão, infringir norma internacional ${ }^{7}$. Ainda, de acordo com a teoria objetiva do mesmo doutrinador, a responsabilização deve ser fundada em três elementos: (i) fato ilícito, comissivo ou omissivo; (ii) resultado lesivo; (iii) nexo causal entre o fato e o resultado lesivo ${ }^{8}$.

Constatada a responsabilidade, este deve reparar as vítimas atingidas, bem como fazer cessar as consequências da violação, de modo que as reparações tendam a fazer desaparecer seus efeitos. Logo, sua natureza e seu montante indenizatório dependem da dimensão dos danos sofridos, analisados tanto no plano material quanto no imaterial, desde que não impliquem enriquecimento ilícito nem empobrecimento para a vítima.

O Estado, então, deve atuar com a devida diligência na proteção que supra a situação de risco ou cesse as circunstâncias que permitem as violações, já que assegurar a responsabilização do Estado significa garantir o respeito aos direitos entre indivíduos.

\footnotetext{
${ }^{6}$ RAMOS, André de Carvalho. Responsabilidade internacional por violação de direitos humanos. Rio de Janeiro: Renovar, 2004. p. 69.

7 Idem, p. 90.

${ }^{8}$ Responsabilidade internacional por violação de direitos humanos: o Brasil e o caso Damião Ximenes. Ludmila Cerqueira Correia. p. 82.
} 


\section{O CASO TRABALHADORES DA FAZENDA BRASIL VERDE VS. BRASIL}

O trabalho escravo no país possui especial relação com a vulnerabilidade dos trabalhadores rurais, de modo que a dificuldade quanto ao acesso à terra, o crescente desemprego da classe e a falta de formação e informação profissionais perpetuam a escravidão.

Em 1995, o Brasil reconheceu pela primeira vez a responsabilidade pelo trabalho escravo que ainda persistia no país, de modo que propôs julgar e punir os responsáveis, bem como aprovar medidas na atuação da prevenção. Entretanto, tal atuação não se mostrou suficiente, tendo em vista ser predominantemente repressiva, não oportunizando medidas alternativas para os trabalhadores.

Posteriormente, no ano de 2003, houve a resolução, por meio de acordo, do caso José Pereira vs. Brasil, representando um marco determinante na história do combate ao trabalho escravo contemporâneo, bem como no avanço da política do país quanto a essa prática escrava. O caso, que dizia respeito ao trabalho em condições análogas à escravidão e à tentativa de homicídio quando da fuga, teve fim com a concretização do acordo, no qual o país reparou financeiramente a vítima pelos danos causados.

Porém, a resolução amistosa do caso ensejou a inércia diante do acordo, haja vista a adoção de políticas públicas, em sua grande maioria, limitadas ao pactuado perante José Pereira.

Nesse contexto, foi apenas recentemente que houve a primeira propositura de ação sobre essa matéria para julgamento da Corte Interamericana de Direitos Humanos quanto ao caso "Trabalhadores da Fazenda Brasil Verde vs. Brasil”. 0 caso refere-se ao trabalho escravo e ao tráfico de pessoas para fins de exploração forçada, de modo que, a partir de seguidas denúncias, houve o resgate de 340 trabalhadores em um período de 14 anos.

A Convenção Americana sobre Direitos Humanos é clara, em seu art. 6ํㅜ, quanto à proibição da escravidão e da servidão:

Artigo 6. Proibição da escravidão e da servidão

1. Ninguém poderá ser submetido a escravidão ou servidão e tanto estas como o tráfico de escravos e o tráfico de mulheres são proibidos em todas as suas formas. 
2. Ninguém deve ser constrangido a executar trabalho forçado ou obrigatório. Nos países em que se prescreve, para certos delitos, pena privativa de liberdade acompanhada de trabalhos forçados, esta disposição não pode ser interpretada no sentido de proibir o cumprimento da dita pena, imposta por um juiz ou tribunal competente. 0 trabalho forçado não deve afetar a dignidade, nem a capacidade física e intelectual do recluso.

A responsabilidade internacional do Estado por violações da Convenção Americana sobre Direitos Humanos decorre de "um contexto no qual dezenas de milhares de trabalhadores foram submetidos anualmente ao trabalho escravo, o qual está enraizado em uma discriminação e exclusão histórica". 9

Pode ser extraído, a partir dos dados do caso, que os indivíduos submetidos a essa forma de trabalho eram, em sua maioria, homens afrodescendentes e com condições econômicas desfavoráveis, provenientes de estados pobres.

Desse modo, o caso reflete a situação de vulnerabilidade social decorrente da pobreza, que ocasionou a desproteção das garantias fundamentais das vítimas, impossibilitadas de acessar os recursos para tutelar seus direitos.

Assim, além da constatação do trabalho escravo, percebeu-se a existência de ameaças de morte devido às incontáveis tentativas de fuga, bem como o desaparecimento forçado de pessoas que tentaram sair da propriedade, incorrendo-se, assim, na violação do direito de ir e vir, consagrado no art. 5o , inciso XV, da Constituição federal, de acordo com a legislação brasileira, e no art. $7^{0}$ da Convenção Americana sobre Direitos Humanos.

O trabalho escravo possuía caráter sistemático na data dos fatos, tendo-se estabelecido com certo padrão de prática, particular e especialmente na região onde ocorreu.

Nesse sentido, a Comissão Interamericana de Direitos Humanos constatou que, a partir das informações disponíveis, os atos praticados na fazenda, como trabalho forçado e servidão por dívidas como forma contemporânea de escravidão, devem incorrer na violação do princípio da não discriminação, bem como na denegação de justiça.

\footnotetext{
${ }_{9}^{9}$ OEA. Comunicado de imprensa. Disponível em:

<http://www.oas.org/pt/cidh/prensa/notas/2015/045.asp>. Acesso em: 9 de abril de 2016.
} 
O caso apresenta-se como emblemático devido à identificação dos obstáculos frequentes e a omissões do Estado na responsabilização das violações e de seus respectivos responsáveis, bem como à intensa perpetuação de entraves à erradicação dessa grave violação de direitos fundamentais, especialmente no Brasil.

Assim, e com base no entendimento da comissão, fica claro que o Brasil depara com a oportunidade de avançar e aperfeiçoar sua legislação e políticas públicas, de modo que consiga ajustar a proteção dos direitos dos trabalhadores e intensifique o combate ao trabalho escravo contemporâneo.

A sentença da corte está prevista para este ano ainda. Espera-se que, para muito além de atuar na reparação dos danos sofridos pelas vítimas, represente importante marco quanto à demarcação de pontos importantes para que o trabalho escravo seja, primeiramente, devidamente identificado, posterior e adequadamente prevenido e, dessa forma, fortemente combatido.

\section{CONCLUSÃO}

Com o objetivo de fomento da discussão, resta claro que o tema abordado, apesar de conhecido desde os primórdios da história, demonstra-se extremamente atual, relevante e recorrente, de modo que deve ser profundamente abordado e incansavelmente contestado.

A ocorrência de violação dos direitos e garantias fundamentais do ser humano, principalmente no ambiente de trabalho, em pleno século XXI, é inaceitável. 0 fato de o caso dos trabalhadores da Fazenda Brasil Verde vs. Brasil ser o primeiro levado a julgamento na Corte Interamericana de Direitos Humanos significa imenso atraso no combate ao trabalho escravo através da adoção de medidas de enfrentamento da discriminação racial.

Por outro lado, não pode ser ignorada a situação segundo a qual, a partir dessa deliberação, o Brasil recebeu a chance de se aperfeiçoar e atuar de modo mais eficaz no combate à escravidão contemporânea, além de ter deparado com a importância da implementação de políticas públicas e medidas legislativas para a erradicação do trabalho escravo, a fim de preencher as lacunas existentes no sistema jurídico vigente. 
Nesse contexto, apesar de todas as dificuldades, o caso ter chegado à corte demonstra um grande passo no avanço da matéria e ele ensejará a criação de jurisprudência sobre o trabalho forçado e as formas contemporâneas de escravidão, de modo que a Corte Interamericana de Direitos Humanos deverá demarcar os parâmetros para os elementos constitutivos dessas violações, na busca da possível responsabilização internacional de determinado Estado pela existência da escravidão e suas consequentes violações.

\section{REFERÊNCIAS}

BOBBIO, Norberto. Liberalismo e democracia. Tradução de Marco Aurélio Nogueira. São Paulo: Brasiliense, 2000.

CAMPOS, Ana Cristina. No Brasil, situação análoga à escravidão atinge 155,3 mil pessoas, diz o relatório Índice de Escravidão Global 2014. Disponível em <http://www.ecodebate.com.br/2014/11/18/no-brasil-situacao-analoga-a-escravidaoatinge-1553-mil-pessoas-diz-o-relatorio-indice-de-escravidao-global-2014/>. Acesso em: 04 de abril de 2016.

CIDH. Relatório n. 95/03: Caso 11.289. Solução Amistosa: José Pereira vs. Brasil. Disponível em <https://cidh.oas.org/annualrep/2003port/Brasil.11289.htm>. Acesso em 07 de abril de 2016.

CIDH. Relatório n. 169/11: Caso 12.066. Admissibilidade e Mérito: Fazenda Brasil Verde vs. Brasil. Doc 53.

CONFORTI, Luciana Paula. Trabalho escravo no Brasil contemporâneo: um olhar além da restrição da liberdade. Disponível em: <http://www.trabalhoescravo.org.br/noticia/79>. Acesso em 03 de abril de 2016.

CORREIA, Ludmila Cerqueira. Responsabilidade internacional por violação de direitos humanos: o Brasil e o caso Damião Ximenes. Prima Facie - ano 4, n. 7, jul/dez 2005.

DELGADO, Maurício Goldinho. Direitos Fundamentais na relação de trabalho. Revista de Direitos e Garantias Fundamentais. n. 2. 2007.

KAUFMAN, Leonardo; OLIVEIRA, Tricia Maria Sá P. O trabalho escravo contemporâneo. Disponível em: <http://www.migalhas.com.br/dePeso/16,MI201403,910410+Trabalho+Escravo+Contemporaneo>. Acesso em 03 de abril de 2016.

LEITE, Gisele. O trabalho em condições análogas ao de escravo no Brasil. Disponível em: <http://www.conteudojuridico.com.br/artigo,o-trabalho-em-condicoes-analogas-ao-deescravo-no-brasil,52310.html\#_ednref2>. Acesso em 04 de abril de 2016. 
MARQUES, Cassius. Direitos e garantias fundamentais. Disponível em: <http://supercassius.jusbrasil.com.br/artigos/111680495/direitos-e-garantiasfundamentais $>$. Acesso em 02 de abril de 2016.

OEA. Comunicado de Imprensa. Disponível em <http://www.oas.org/pt/cidh/prensa/notas/2015/045.asp>. Acesso em 09 de abril de 2016.

OIT. Convenção 105: Convenção Relativa a Abolição do Trabalho Forçado. Disponível em <http://www.oit.org.br/sites/all/forced_labour/oit/convencoes/conv_105.pdf>. Acesso em 06 de abril de 2016.

OIT. Convenção 29: Sobre o Trabalho Forçado ou Obrigatório. Disponível em <http://www.oit.org.br/sites/all/forced_labour/oit/convencoes/conv_29.pdf>. Acesso em 06 de abril de 2016.

OIT. Uma Aliança Global Contra o Trabalho Forçado: Relatório Global do Seguimento da Declaração da OIT sobre Princípios e Direitos Fundamentais no Trabalho 2005. Disponível em <http://www.oit.org.br/sites/all/forced_labour/oit/relatorio/relatorio_global2005.pdf >. Acesso em 06 de abril de 2016.

PANTALEÃO, Sérgio Ferreira. Trabalho escravo - triste realidade. Disponível em: <http://www.guiatrabalhista.com.br/tematicas/trabalho_escravo.htm>. Acesso em 02 de abril de 2016.

PEDRO, Bruno Lessa Pedreira São. Trabalho escravo e dano moral. Disponível em: $<$ http://www.ambitojuridico.com.br/site/?n_link=revista_artigos_leitura\&artigo_id=12084>. Acesso em 03 de abril de 2016.

RAMOS, André de Carvalho. Responsabilidade internacional por violação de direitos humanos. Rio de Janeiro: Renovar, 2004. 